\title{
Antibodies elicited in adults by a primary Plasmodium falciparum blood-stage infection recognize different epitopes compared with immune individuals

\author{
Damon P Eisen*1,2, Lina Wang3 ${ }^{3}$, Helene Jouin ${ }^{4}$, E Elsa H Murhandarwati ${ }^{3}$, \\ Casilda G Black ${ }^{3}$, Odile Mercereau-Puijalon ${ }^{4}$ and Ross L Coppel ${ }^{3}$
}

Address: ${ }^{1}$ Clinical Centre for Research Excellence in Infectious Diseases, Victorian Infectious Diseases Service, Royal Melbourne Hospital, Grattan St, Parkville, Victoria, 3050, Australia, ${ }^{2}$ Malaria and Scabies Unit, Queensland Institute of Medical Research, Herston, Queensland, 4029, Australia, ${ }^{3}$ Department of Microbiology, Monash University, Clayton, Victoria, 3800, Australia and ${ }^{4}$ Unite d'Immunologie Moléculaire des Parasites, Institut Pasteur, Paris, France

Email: Damon P Eisen* - damon.eisen@mh.org.au; Lina Wang - lina.wang@med.monash.edu.au; Helene Jouin - hajouin@pasteur.fr; E Elsa H Murhandarwati - Elsa.Murhandarwati@med.monash.edu.au; Casilda G Black - casilda.black@med.monash.edu.au; Odile MercereauPuijalon -omp@pasteur.fr; Ross L Coppel - ross.coppel@med.monash.edu.au

* Corresponding author

Published: 2 July 2007

Malaria Journal 2007, 6:86 doi:10.1 186/1475-2875-6-86
Received: I March 2007

Accepted: 2 July 2007

This article is available from: http://www.malariajournal.com/content/6/l/86

(c) 2007 Eisen et al; licensee BioMed Central Ltd.

This is an Open Access article distributed under the terms of the Creative Commons Attribution License (http://creativecommons.org/licenses/by/2.0), which permits unrestricted use, distribution, and reproduction in any medium, provided the original work is properly cited.

\begin{abstract}
Background: Asexual stage antibody responses following initial Plasmodium falciparum infections in previously healthy adults may inform vaccine development, yet these have not been as intensively studied as they have in populations from malaria-endemic areas.
\end{abstract}

Methods: Serum samples were collected over a six-month period from twenty travellers having returned with falciparum malaria. Fourteen of these were malaria-naïve and six had a past history of one to two episodes of malaria. Antibodies to seven asexual stage $P$. falciparum antigens were measured by ELISA. Invasion inhibitory antibody responses to the $19 \mathrm{kDa}$ fragment of merozoite surface protein I $\left(\mathrm{MSPI}_{19}\right)$ were determined.

Results: Short-lived antibody responses were found in the majority of the subjects. While MSPI ${ }_{19}$ antibodies were most common, MSPI block 2 antibodies were significantly less frequent and recognized conserved domains. Antibodies to MSP2 cross-reacted to the dimorphic allelic families and anti-MSP2 isotypes were not IgG3 skewed as shown previously. MSPI ${ }_{19}$ invasion inhibiting antibodies were present in 9/20 patients. A past history of malaria did not influence the frequency of these short-lived, functional antibodies ( $p=0.2$, 2-tailed Fisher's exact test).

Conclusion: Adults infected with $P$. falciparum for the first time, develop relatively short-lived immune responses that, in the case of $\mathrm{MSPI}_{19}$, are functional. Antibodies to the polymorphic antigens studied were particularly directed to allelic family specific, non-repetitive and conserved determinants and were not lgG subclass skewed. These responses are substantially different to those found in malaria immune individuals. 


\section{Background}

Understanding the native immune response to Plasmodium falciparum infection is an important prerequisite for successful vaccine development against this high priority global disease. Many population studies performed in areas of malaria transmission have correlated the presence of antibodies to $P$. falciparum proteins with protection from disease. In general, the non-sterilizing immunity to malaria seen in adults living in areas hyperendemic for malaria is acquired after numerous infections. Little, however, is known about antibody responses in previously healthy adults after single infections with $P$. falciparum, such as non-immune travellers.

Based on current information, a number of proteins are being advanced as potentially useful components of a subunit malaria vaccine. For example, $\mathrm{MSP}_{19}$, the carboxyl-terminal domain of merozoite surface protein-1 (MSP1) is highly conserved [1], serves a critical function in erythrocyte invasion [2] and has been widely shown to confer protective immunity in various models of malaria infection [3]. The repetitive, block 2 region of MSP1 has been identified as a major immune target by studies that infer immune selection acting upon it and there is a strong association between antibodies to this region and protection [4]. Other proteins, such as MSP2, have been shown in recent field studies of a combination vaccine to induce protective immune responses against homologous strains of malaria [5]. The problem of antigenic diversity can be extreme for some malaria proteins, such as MSP2 and apical membrane antigen-1, and, accordingly, there has been interest in relatively invariant proteins, such as MSP4 [6] and MSP5 [7] that show good degrees of protection against heterologous challenge in model systems of malaria infection [8]. Other conserved proteins, such as MSP6, MSP7 [9] and rhoptry associated membrane antigen (RAMA) [10] induce strong responses during infection and an association has been shown between antibody response and clinical immunity $[10,11]$.

This study has assessed the immune responses in nonimmune adults mostly presenting with their first episode of $P$. falciparum infection and characterized the pattern of acquisition of antibodies to seven asexual stage proteins. By systematically collecting a series of samples from these individuals the timing, level and decline of these antibodies has been characterized and a comparison of the immunogenicity of various antigens been made. Antibody responses to overlapping, dimorphic family specific epitopes of MSP1 block 2 and dimorphic family specific repetitive and non-repetitive regions of MSP2 were analysed to determine the specificity of responses to these targets. Immunoglobulin isotyping was performed for antibodies to MSP1 $1_{19}, \mathrm{MSP} 2, \mathrm{MSP} 4$ and MSP7B, where previous data have indicated isotype bias to assess whether these patterns were present. Finally, the functionality of antibodies formed against $\mathrm{MSP}_{19}$ in a growth inhibition assay has been measured.

\section{Methods \\ Blood samples}

Full blood and serum samples were collected with written informed consent from twenty patients presenting to the Royal Brisbane and Princess Alexandra Hospitals with falciparum malaria. The Human Research Ethics Committees of the Royal Brisbane and Princess Alexandra Hospitals granted approval for the study. Parasitized erythrocytes were stored in $8 \mathrm{M}$ GuHC1. Serum samples were collected at around the time of diagnosis of $P$. falciparum infection then again at approximately one month and six months after infection. Negative controls consisted of 30 samples taken with informed consent from Australian blood donors with no history of exposure to malaria. Positive control sera consisted of samples taken with informed consent from 20 hyperimmune, Papua New Guinean (PNG) adults. The serum samples were stored at $-70^{\circ} \mathrm{C}$.

\section{MSPI block 2 and MSP2 genotyping}

A strategy was instituted to detect multiple infections to aid the interpretation of antibody responses to MSP1 block 2 and MSP2 dimorphic family alleles. MSP1 block 2 alleles were amplified and sequenced directly as previously described [12]. MSP2 alleles were amplified by PCR utilising dimorphic family specific oligonucleotides [13]. This approach identified specimens with multiple polymorphic alleles.

\section{Recombinant proteins}

$\mathrm{MSP}_{19}$ (Wellcome strain) was expressed as previously [14]. MSP2 proteins representing; i) the full-length dimorphic family allele (MSP2/3D7 and MSP2/FC27), ii) full length with central repeat region deleted, ie dimorphic family specific non-repetitive region (MSP2/3D7 nonrepetitive and MSP2/FC27 non-repetitive) and iii) conserved region alone (MSP2 CR) were expressed as described previously [15]. Full length MSP4 [6], MSP5 [7] and MSP6/MSP7 [9] were all expressed as previously. RAMA-E, the C-terminal erythrocyte-binding domain of RAMA was expressed as previously [10]. All proteins were expressed as GST-fusions, except for MSP4 and MSP6 which were expressed with a C-terminal hexahistidine tag. The conformational fidelity of a number of these proteins cans be confirmed. Reduction and alkylation of the $\mathrm{MSP}_{1}{ }_{19}$ recombinant protein has been shown to abolish its reactivity with several inhibitory monoclonal antibodies [14], as well as reduce its recognition by human immune sera [16]. Similar data are available for MSP4 and MSP 5 (Lina Wang, personal communication). 


\section{Antibody measurements}

The reactivity of human sera with recombinant proteins and detection of the Ig isotypes of the antigen-specific antibodies, using an isotype-specific method, were examined by ELISA as previously described [17]. Serum samples were diluted 1:500. Positive sera were defined as those that give an absorbance, measured as an optical density (OD) value, greater than the mean plus two standard deviations of absorbance obtained with sera taken from 30 Australian blood donors with no history of exposure to malaria. Positive control sera consisted of pooled samples from 20 hyperimmune, PNG adults. By coating microtitre plates with reference serum and incubating with the human isotype-specific monoclonal antibodies, the absorbances obtained were compared with the actual values for the reference serum and used to calculate compensation factors for the different isotypes, which are the ratios of the absorbance for the given isotype to that of IgG1. The derived compensation factors for IgG1, IgG2, IgG3, and IgG4 were $1,0.37,1.07$, and 1.71 respectively, and they were used to adjust the ELISA values. Immunoglobulin isotypes were determined on the 20 PNG samples individually to allow comparison with the returned traveller samples.

\section{ELISA with MSPI block 2 biotinylated peptides}

A set of 82 overlapping 15-mer peptides encompassing all the sequences of the allelic forms of the MSP1 block 2 [1], was synthesized by Chiron Mimotopes Pty. Ltd. (Clayton, Victoria, Australia). The sequences of the peptides are described in a previous study [18]. ELISA with biotinylated peptides was performed as previously described [18]. Each plasma sample was tested in duplicate. The wells that gave a signal two times greater than the OD value of the wells without peptide were considered positive.

\section{Growth inhibition mediated by $\mathrm{MSPI}_{19}$ antibodies}

Growth inhibition assays comparing P. falciparum (D10 strain) and transfected $P$. falciparum expressing the $19 \mathrm{kDa}$ C-terminal fragment of MSP1 from $P$. chabaudi were performed as previously described [2] to determine the effect of antibodies specific for $\mathrm{MSP}_{19}$ on parasite growth. In brief, mature stages from synchronized parasite cultures were incubated with patient and control, pooled nonimmune human serum diluted to $1: 10$, for 26 hours to allow for schizont rupture and merozoite invasion. Invasion inhibition for each parasite line was assessed microscopically by comparing parasitaemia observed in the presence of test and non-immune serum.

\section{Statistical analysis}

The frequency of positive antibody responses was compared using the Chi-squared test. Comparisons between non-parametric variables such as median ODs and immu- noglobulin isotype ODs were performed using the MannWhitney test. Correlations between independent variables were performed using Pearson's coefficient. Invasion inhibition due to $\mathrm{MSP} 1_{1}$ antibodies was determined by comparing mean invasion rates for the two parasite lines using a two-sample Student's $t$ test. All statistical analyses were carried out in Minitab ${ }^{\circledast}$ Release 14 .

\section{Results \\ Patients}

Twenty patients participated in the study. There were ten male and ten female patients. The median age was 34 years. Twelve patients acquired $P$. falciparum in the Western Pacific region (PNG or the Solomon Islands), six in Africa and two in Asia. There were no mixed infections. The median parasitaemia was $24,900 / \mu \mathrm{L}(740-326,000 /$ $\mu \mathrm{L})$. Fourteen of the patients had not had $P$. falciparum previously. These patients were returning travellers from malaria endemic areas. One other returned traveller had two earlier episodes of $P$. falciparum in the six months before the study episode. Five patients were born in malaria endemic areas and had a past history of malaria occurring between approximately 20 years and 3 months before this study. These six patients had one or two previous episodes of malaria.

Fifty-five samples were collected from the 20 returned travellers. At around the time of diagnosis (0-2 weeks) 21 samples were collected. At approximately one month post diagnosis (4-8 weeks) 11 samples were collected and at up to six months post diagnosis (10-41 weeks) 23 samples were collected. Multiple samples were available from some travellers at some of these time points.

\section{Frequency of positive antibody responses (Table I and 2)} Antibody responses in patient sera were measured against the seven asexual stage antigens (MSP1, MSP2, MSP4, MSP5, MSP6/7, and RAMA-E). Positive antibody responses as defined above were counted in any of the samples from a study patient. The highest frequency of positive antibody responses to the blood stage antigens

Table I: Rates of positive antibody responses measured by ELISA to merozoite surface proteins

\begin{tabular}{lc}
\hline & Proportion +ve serology \\
\hline MSPI $_{19}$ & $19 / 20$ \\
FC27 non-repetitive & $18 / 20$ \\
FC27/3D7 non-repetitive & $17 / 20$ \\
3D7 & $16 / 20$ \\
MSP2 conserved region/MSP6/RAMA-E & $15 / 20$ \\
MSP4/MSP5 & $14 / 20^{\mathrm{a}}$ \\
MSP7 & $13 / 20^{\mathrm{a}}$ \\
MSPI block 2 & $4 / 20^{\mathrm{b}}$
\end{tabular}

\footnotetext{
${ }^{a}$ proportion +ves $<\mathrm{MSPI}_{19}, \mathrm{p}<0.05$
}

${ }^{b}$ proportion +ves $<\mathrm{MSPI}_{19}, \mathrm{P}<0.0001$ 
Table 2: Antibody responses compared with negative control sera and in relation to time since infection, past infection and parasitaemia

\begin{tabular}{|c|c|c|c|c|c|c|c|c|c|c|c|}
\hline Median optical density & $\mathrm{MSPI}_{19}$ & MSP2 3D7 & MSP2 FC27 & $\begin{array}{l}\text { MSP2 3D7 } \\
\text { non- } \\
\text { repetitive }\end{array}$ & $\begin{array}{c}\text { MSP2 FC27 } \\
\text { non- } \\
\text { repetitive }\end{array}$ & $\begin{array}{l}\text { MSP2 } \\
\text { conserved } \\
\text { region }\end{array}$ & MSP4 & MSP5 & MSP6B & MSP7B & RAMA-E \\
\hline Overall $(n=55)$ & $1.273^{\mathrm{a}}$ & $0.296^{a}$ & $0.285^{a}$ & $0.939 a$ & $0.456^{a}$ & $0.291^{a}$ & $0.578^{a}$ & $0.35^{\mathrm{a}}$ & $0.099 a$ & $0.295^{a}$ & $0.09 \mathrm{I}^{\mathrm{a}}$ \\
\hline $0-2$ weeks $(n=21)$ & $2.95^{\mathrm{a}}$ & $0.421^{a}$ & $0.68 \mathrm{I}^{\mathrm{a}}$ & $1.095^{a}$ & $0.635^{a}$ & $0.362^{\mathrm{ac}}$ & $0.885^{a}$ & $0.407^{a}$ & $\left.0.14\right|^{\text {ac }}$ & $0.582^{\mathrm{a}}$ & $0.089 a$ \\
\hline 4-8 weeks $(n=11)$ & $1.65^{\mathrm{ad}}$ & $0.538^{a}$ & $0.5 \mathrm{II}$ & $1.84 \mathrm{I}_{\mathrm{ad}}$ & $0.597^{\mathrm{ad}}$ & $0.344^{\text {ad }}$ & $0.694^{a}$ & $0.412^{\mathrm{ad}}$ & $0.154^{\text {ad }}$ & $0.295^{a}$ & $0.192^{\mathrm{ad}}$ \\
\hline$|0-4|$ weeks $(n=23)$ & $0.46^{\mathrm{a}}$ & $0.137 \mathrm{a}$ & $0.15 \mathrm{I}^{\mathrm{a}}$ & $0.497 \mathrm{a}$ & $0.23^{a}$ & $0.146^{a}$ & $0.415^{\mathrm{a}}$ & $0.292^{\mathrm{a}}$ & $0.047^{a}$ & $0.25^{\mathrm{a}}$ & $0.057^{a}$ \\
\hline No past infection $(n=37)$ & $\left.0.68\right|_{\text {ae }}$ & $0.157^{a}$ & $0.229 a$ & $0.849 a$ & $0.413^{a}$ & $0.32^{\mathrm{a}}$ & $0.6 \mathrm{I}^{\mathrm{a}}$ & $0.24^{\text {af }}$ & $0.068^{a}$ & $0.284^{\mathrm{a}}$ & $0.089 a$ \\
\hline Past infection $(n=18)$ & $2.82^{\mathrm{a}}$ & $0.975^{a}$ & $0.748^{a}$ & $1.098^{a}$ & $0.598^{a}$ & $0.274^{\mathrm{a}}$ & $0.463^{\mathrm{a}}$ & $0.402^{\mathrm{a}}$ & $0.121^{\mathrm{a}}$ & $0.404^{\mathrm{a}}$ & $0.114^{a}$ \\
\hline Lower quartile parasitaemia $(n=14)$ & $0.252^{\mathrm{a}}$ & $0.10 I^{a}$ & $0.08^{b}$ & $0.656^{\mathrm{a}}$ & $0.18^{\mathrm{bg}}$ & $0.22 I^{b}$ & $0.419 b$ & $0.335^{b}$ & $0.043^{b}$ & $0.285^{b}$ & $0.075^{b}$ \\
\hline Upper quartile parasitaemia $(n=14)$ & $0.83^{\mathrm{a}}$ & $0.157^{a}$ & $0.428^{a}$ & $0.684^{a}$ & $0.645^{a}$ & $0.525^{a}$ & $0.708^{b}$ & $0.198^{b}$ & $0.069 \mathrm{a}$ & $0.176^{a}$ & $0.07 I^{a}$ \\
\hline Negative control $(n=30)$ & -.004 & 0.009 & 0.015 & 0.061 & 0.044 & 0.069 & 0.086 & 0.074 & 0.010 & 0.055 & 0.013 \\
\hline
\end{tabular}

a differs from neg controls $p<0.0001$

b differs from neg controls $p<0.05$

c Timepoint I vs timepoint 3 median difference $p<0.05$

d Timepoint 2 vs timepoint 3 median difference $p<0.05$

e No past infection vs past infection median difference $p<0.05$

$f$ No past infection vs past infection median difference $p<0.01$

$\mathrm{g}$ Lower vs upper quartile parasitaemia median difference $\mathrm{p}<0.05$

tested was to MSP119 (19/20). Importantly, 15/20 patients had antibodies to the conserved region of MSP2. A significantly lower frequency of positive antibody responses compared with MSP119 antibodies were seen for MSP4/MSP5 (14/20), MSP7 (13/20) and MSP1 block 2 antibodies (4/20) (Table 1). Median antibody levels from $P$. falciparum cases were significantly higher than median negative control antibodies for all antigens tested (Table 2).

\section{Time course of antibodies, influence of past infection and parasitaemia (Table 2)}

Median absorbances were significantly greater than negative control results at the first time point at around $0-2$ weeks after infection. The general trend in absorbances was for levels to be unchanged at 4-8 weeks and to decline significantly after 10 weeks. At the last time point measured, the median absorbances for all antigens tested remained higher than negative controls. Samples were grouped according to whether patients had a history of previous malaria or not. Median absorbances were significantly higher in patients with past malaria infection only for anti-MSP $1_{19}$ and anti-MSP5 responses. Otherwise, for all other antigens tested, the median absorbances did not differ according to whether patients had a previous history of malaria or not. Peripheral blood parasite counts appeared to have little impact on the antibody response for most antigens tested. The only antibody response where there was a significant difference in the median ODs between patients in the upper $(67,000 / \mu \mathrm{L})$ and lower $(14,484 / \mu \mathrm{L})$ parasitaemia quartiles was against MSP2/FC27 non-repetitive regions. There was no significant correlation between parasite counts and antibody levels for any antigen.

\section{MSP2 antibody responses (Table 3)}

Responses to recombinant MSP2 antigens containing various family specific and conserved regions of the molecule in the first patient sample collected were correlated to assess for cross-reactive specificities. Patient samples from $P$. falciparum infections containing multiple MSP2 family alleles were identified by the MSP2 dimorphic family specific PCR. Three patient samples had multiple 3D7 and FC27 family alleles, 11 had single 3D7 alleles and four had single FC27 alleles. In two samples, MSP2 alleles could not be determined. Cross-allelic family reactive antibodies were found in this study, as there were significant correlations between the responses to 3D7 and FC27 recombinant antigens. Firstly, correlations of responses in all patients, malaria-naïve or previously exposed, were analysed. (Table 3a) Significant correlations were found in the entire sample set (ie. single 3D7 or FC27 infections, multiple 3D7/FC27 allelic and untypeable infections) but were also present when sera from patients shown to have single infections with 3D7 alleles alone were analysed. Significant correlations were present between antibodies to the conserved region of MSP2 and the dimorphic family specific non-repetitive MSP2 allelic and, to a lesser extent, full length MSP2 family constructs. The correlation between MSP2 conserved region and dimorphic family specific non-repetitive MSP2 allelic family constructs was most pronounced when the sera from 3D7 infections alone were analysed. When the samples from malarianaïve patients alone were analysed (Table 3b), crossallelic family reactions were also present, but to a lesser extent. These are shown by the significant correlations present between the FC27 non-repetitive construct and the conserved region in 3D7 allelic family infected individuals and between 3D7 recombinant antigens in FC27 allelic family infected individuals. 
Table 3: Correlation of antibody responses to MSP2 recombinant antigens expressing allelic family specific and conserved regions; a, antibodies in all patients $b$, antibodies in naïve patients

\begin{tabular}{|c|c|c|c|c|}
\hline & \multicolumn{4}{|c|}{ Pearson's correlation coefficients ( $r$ ) } \\
\hline & 3D7 non-repetitive & FC27 & FC27 non-repetitive & MSP2 conserved region \\
\hline \multicolumn{5}{|c|}{ All infections ( $n=20,2$ non-typeable) } \\
\hline 3D7 & $0.96^{a}$ & $0.5 \mathrm{I}^{\mathrm{b}}$ & 0.42 & $0.55^{b}$ \\
\hline 3D7 non-repetitive & & $0.48^{\mathrm{b}}$ & 0.4 & $0.67^{\mathrm{a}}$ \\
\hline $\mathrm{FC} 27$ & & & $0.85^{\mathrm{a}}$ & 0.13 \\
\hline FC27 non-repetitive & & & & 0.27 \\
\hline \multicolumn{5}{|c|}{ All single allelic family infections $(n=15)$} \\
\hline 3D7 & $0.94^{a}$ & $0.55^{\mathrm{b}}$ & 0.18 & 0.33 \\
\hline 3D7 non-repetitive & & 0.48 & 0.17 & 0.51 \\
\hline FC27 & & & $0.83^{a}$ & 0.13 \\
\hline FC27 non-non-repetitive & & & & 0.17 \\
\hline \multicolumn{5}{|c|}{ Single 3D7 infections $(n=11)$} \\
\hline 3D7 & $0.95^{\mathrm{a}}$ & $0.89 a$ & $0.78^{b}$ & 0.6 \\
\hline 3D7 non-repetitive & & $0.82^{\mathrm{b}}$ & $0.85^{\mathrm{a}}$ & $0.72^{b}$ \\
\hline FC27 & & & 0.57 & 0.43 \\
\hline FC27 non-repetitive & & & & $0.92^{\mathrm{a}}$ \\
\hline \multicolumn{5}{|c|}{ Single FC27 infections $(n=4)$} \\
\hline 3D7 & $0.96^{b}$ & 0.33 & -0.14 & -0.35 \\
\hline 3D7 non-repetitive & & 0.39 & -0.12 & -0.24 \\
\hline FC27 & & & 0.87 & -0.81 \\
\hline FC27 non-repetitive & & & & -0.78 \\
\hline \multicolumn{5}{|c|}{ Multiple 3D7/FC27 infections $(n=3)$} \\
\hline 3D7 & 0.98 & 0.79 & 0.89 & 0.63 \\
\hline 3D7 non-repetitive & & 0.67 & 0.79 & 0.76 \\
\hline $\mathrm{FC} 27$ & & & 0.98 & 0.03 \\
\hline FC27 non-repetitive & 0.21 & & & \\
\hline
\end{tabular}

a $p<0.001$

$b_{p}<0.05$

\section{Immunoglobulin isotypes (Table 4)}

The isotypes of anti-merozoite surface protein antibodies were compared among sera from study subjects and sera from long-term residents of PNG who had experienced multiple malaria infections. Significantly lower median titres were seen in IgG2 responses to the MSP2 FC27 allele and MSP4 in study patients compared to PNG residents. Similarly, IgG3 responses to the MSP2 3D7 and FC27 allelic families and MSP7 were lower than in PNG controls. Correlations between IgG1 and IgG3 responses were compared in study and PNG control sera. In study and control sera, there was a strong IgG1 predominance for $M S P 1_{19}$. The expected bias to IgG3 for anti-MSP2 and anti-MSP4 responses was not present in the study sera, but instead there was IgG1 predominance, although less marked than for MSP $1_{19}$. Comparison of IgM responses in study patients who were naïve and those who had a previous history of malaria showed no significant differences for all antibodies tested.

Table 4: Comparison of median optical densities of immunoglobulin isotypes between study samples and PNG, positive control sera.

\begin{tabular}{|c|c|c|c|c|c|}
\hline & $\mathrm{MSPI}_{19}$ & MSP2 3D7 & MSP2 FC27 & MSP4 & MSP7B \\
\hline $\lg G \mid$ & NSa & NS & NS & NS & $0.016: 0.044 b$ \\
\hline $\lg G 2$ & NS & NS & $0.005: 0.024 b$ & $0.038: 0.017 c$ & NS \\
\hline $\lg G 3$ & NS & $0.009: 0.09 b$ & $0.003: 0.35^{b}$ & NS & $0.001: 0.155^{c}$ \\
\hline $\lg G 4$ & NS & NS & NS & NS & $-0.002: 0.006 c$ \\
\hline $\lg M$ & NS & NS & NS & NS & NS \\
\hline
\end{tabular}

a not significantly different

$b_{p}<0.05$

c $p<0.001$ 


\begin{tabular}{|c|c|c|c|c|}
\hline & \multicolumn{4}{|c|}{ Pearson's correlation coefficients $(r)$} \\
\hline & 3D7 non-repetitive & $\mathrm{FC} 27$ & FC27 non-repetitive & MSP2 conserved region \\
\hline \multicolumn{5}{|c|}{ All infections ( $n=14,2$ non-typeable) } \\
\hline 3D7 & $0.94^{a}$ & 0.25 & 0.24 & 0.5 \\
\hline 3D7 non-repetitive & & 0.21 & 0.24 & $0.64 b$ \\
\hline FC27 & & & $0.92^{\mathrm{a}}$ & -0.17 \\
\hline FC27 non-repetitive & & & & 0.21 \\
\hline \multicolumn{5}{|c|}{ All single allelic family infections $(n=10)$} \\
\hline 3D7 & $0.85^{b}$ & 0.45 & 0.17 & -0.12 \\
\hline 3D7 non-repetitive & & 0.31 & 0.11 & 0.12 \\
\hline FC27 & & & $0.93^{a}$ & -0.11 \\
\hline FC27 non-non-repetitive & & & & 0.03 \\
\hline \multicolumn{5}{|c|}{ Single 3D7 infections $(n=6)$} \\
\hline 3D7 & 0.81 & 0.74 & 0.36 & 0.03 \\
\hline 3D7 non-repetitive & & 0.45 & 0.63 & 0.46 \\
\hline FC27 & & & 0.32 & 0.09 \\
\hline FC27 non-repetitive & & & & $0.89 \mathrm{~b}$ \\
\hline \multicolumn{5}{|c|}{ Single FC27 infections $(n=4)$} \\
\hline 3D7 & $0.96^{\mathrm{b}}$ & 0.33 & -0.14 & -0.35 \\
\hline 3D7 non-repetitive & & 0.39 & -0.12 & -0.24 \\
\hline FC27 & & & 0.87 & -0.81 \\
\hline FC27 non-repetitive & & & & -0.78 \\
\hline
\end{tabular}

a $\mathrm{p}<0.001$

${ }^{b} p<0.05$

\section{MSPI Block 2 antibody responses}

Antibodies to the MSP1 block 2 epitopes were found in a minority of patients $(4 / 20)$. In these patients, antibodies were found to be restricted to one allelic family type in three of the four patients and were also restricted to a maximum of four epitopes. The same temporal pattern as with the other antigens was found with relatively high absorbances at the time of infection followed by a reduction over the next six months. In one patient, antibodies to a single $\mathrm{K} 1$ and RO33 family allele could be detected. This individual had no past history of malaria infection. Genotyping of the MSP1 block 2 PCR showed the presence of a single $\mathrm{K} 1$ dimorphic family allele in this individual.

\section{Growth inhibition due to $\mathrm{MSPI}_{19}$ antibodies}

Significant invasion inhibiting anti-MSP1 $1_{19}$ antibodies were detected in a total of nine patient samples. In these samples, there was a $14.8-48.7 \%$ reduction of red blood cell invasion when $P$. falciparum was compared with the $P$. falciparum $\mathrm{MSP}_{19}-P$. chabaudi transfectant. The antibodies were short-lived, being present soon after the patent infection (median 36 days; range 9-249 days) and declining in 5/9 cases (tested negative at median 185 days post infection; range 170 - 236 days.). In three cases, the invasion inhibiting antibodies were detected using the standard assay conditions and serum dilution of 1:10. However, nine serum samples caused inhibition of sch- izont rupture, which interfered with assessment of growth inhibition at the standard dilution. When these sera were diluted to 1:90, six were found to contain invasion inhibiting anti-MSP $1_{19}$ antibodies invasion. There was no difference in frequency of these functional MSP1 19 antibodies according to whether patients had a past history of malaria or not ( $\mathrm{p}=0.2,2$-tailed Fisher's exact) but anti-MSP $1_{19}$ absorbances were significantly higher in the group with invasion inhibiting antibodies (2.31 vs. $0.49 \mathrm{p}$ $<0.05)$.

\section{Discussion}

Antibody responses to malaria in people living in endemic regions are complex and represent the summation of multiple infections, typically beginning in infancy. Repeated infections are required to stimulate the non-sterile immunity found in adults living in malaria hyperendemic areas. Little is known about the immune responses to a single $P$. falciparum infection. In the group of previously healthy, mostly $P$. falciparum naïve, adults studied here, antibodies were measured to seven different malaria proteins including multiple MSP1 and MSP2 regions and alleles. Relatively short-lived antibody responses were found most commonly with MSP4/5/7 and MSP1 block 2 antibodies being significantly less frequent than the rest of the antibodies tested. In nine subjects, functional, invasion inhibiting $\mathrm{MSP}_{19}$ antibodies were shown to be 
present. Importantly, frequent antibody reactions to conserved regions of MSP2 have been documented for the first time in humans exposed to a single $P$. falciparum infection. Similarly, the MSP2 isotype response was not skewed towards IgG3 antibodies as previously shown [19]. These features of the immune response to $P$. falciparum seen in naïve adults contrast markedly with the MSP2 repeat region dominated response found in malaria endemic populations [19].

MSP1 ${ }_{19}$ appeared to be particularly immunogenic in this population as shown by the presence of invasion inhibiting antibodies in 9/20 patients that were present one month after infection but mostly disappeared by six months. Of interest, a significant proportion (45\%) of sera inhibited schizont rupture in growth assays, a property much more rarely encountered in sera from endemic areas (data not shown). Dilution of these sera revealed an underlying capacity to inhibit merozoite invasion. Functional $\mathrm{MSP}_{19}$ antibodies, as detected by this method, were correlated with protection from $P$. falciparum infection in Kenyan children and adults while MSP1 ${ }_{19}$ antibodies measured by ELISA were not [20]. Other studies do not show the same level of correlation and the exact protective importance of this antibody subpopulation is not yet defined in all populations [21,22]. Nevertheless, it seems reasonable to suggest that the presence of such antibodies indicates a capacity of convalescent sera to exert a level of anti-parasitic action after a single infection. It will be particularly interesting to discover whether similar levels of inhibitory antibodies are induced in children resident in endemic areas, after their first bout of malaria. This may represent a previously unrecognized mechanism for shortterm host protection.

MSP1 block 2, by contrast, was much less antigenic. Only $4 / 20$ of the adult population were positive for any MSP1 block 2 antibodies. This contrasts with previous field studies that also measured MSP1 block 2 antibodies to allelic family specific, short peptides. An age-dependant increase in antibodies to $58.3 \%$ of $10-15$ year old Ghanaian children was found [23]. The low frequency of antibodies MSP1 block 2 in this study does not appear to be due to failure to detect short-lived antibodies [24] as the patients were assayed immediately after their clinical episode of malaria with fine epitope mapping using 15 mer peptides that cover the MSP1 block 2 locus with significant redundancy. The epitopes recognized in this study were all from relatively constant regions of the MSP1 block 2 alleles. One patient who had no past history of malaria infection had antibodies detected to both $\mathrm{K} 1$ and RO33 allelic family antigens despite being infected with only a K1 family isolate. The observed low antigenicity of MSP1 block 2 in adults mostly after their first $P$. falciparum infection suggests that the potentially protective antibodies to this region [23] reflect a high frequency of previous episodes of malaria. The other antigens assayed with relatively low levels of seroreactivity were MSP4/5 and MSP7, which, like MSP1 block 2, appear to have higher rates of seropositivity in malaria endemic populations $[9,17]$.

For the first time, in this study, there is evidence of commonly occurring antibody responses to the conserved regions of MSP2. This contrasts with prevailing evidence that suggests the immunodominance of the central amino acid repeat region following repeated infections of humans [19] or immunization studies [25]. Antibody responses to the conserved regions of MSP2 were documented in 15/20 of study patients. By contrast, antibodies from pooled PNG adult serum to this region were below the cut-off level so this result is highly significant. When the same methodology was used to study semi-immune Vietnamese teenagers and adults, only 1/15 had antibodies to the MSP2 conserved region [15]. No measurable antibodies to the conserved regions of MSP2 were induced by vaccination with the 3D7 allele in five to nine year old children in the Combination B trial [25]. A minority of non-immune Swiss travellers have been shown to have antibodies to the conserved regions of MSP2 by non-quantitative immunoblot [26].

Additionally, significant correlations between MSP2 allelic family constructs have been shown. More significant correlations between antibodies were found in individuals with a past history of one to two episodes of malaria. Even in previously naïve individuals, apparently cross-allelic family reactive antibodies were present. It appears that these are attributable to antibodies to the conserved region of MSP2. The correlations we have calculated are based on small numbers of samples. Previous studies of anti-MSP2 immune responses in populations living in hyperendemic areas have shown that antibodies are dimorphic family specific [19], but that there is extensive intra-dimorphic family immune response cross-reactivity [27]. Vaccine-derived MSP2 antibodies were restricted to the $3 \mathrm{D} 7$ specific regions of the vaccine antigen [25]. Limited inter-dimorphic family antibody cross reactivity has been recognized previously for MSP2 after patent malaria in two non-immune patients [26] and in this study, inter allelic family specific antibodies to MSP1 block 2 were found in one patient.

Protective antibodies to repeat regions of MSP2 have been shown to change from IgG1 to IgG3 dominated responses with aging indicating a maturation of the immune response $[28,29]$. The patients studied here do not show this same isotype pattern and MSP2 antibodies were predominantly IgG1. Thus, these non-immune adults studied herein have MSP2 responses that differ in target and isotype from hyperimmune sera. It may be that the repeat 
region dominated $\mathrm{MSP} 2$ responses seen in malaria endemic regions result from the repeated infections experienced by infants with immature immune systems that do not recognise the conserved regions of MSP2. Similarly, the IgG3 dominated anti-MSP7 response in immune adults [9] was not seen in this study population. Previously naïve patients were also not found to have higher IgM responses to any of the antigens tested than adults with a past history of malaria.

Antibody responses trended to declining levels over the 6 months of follow up. At the final bleed though, antibodies to all antigens tested remained positive. The level of parasitaemia, not unexpectedly, had essentially no influence on the level of antibodies measured. In field settings with seasonal malaria transmission, $\mathrm{MSP}_{19}$ and MSP1 block 2 antibodies have been shown to decrease over dry seasons [24]. Antibodies to chondroitin sulphate A-binding variant surface antigens have also been shown to be short-lived in women with pregnancy associated malaria but their presence correlates with protection against infection of the placenta [30]. Temporary humoral immune responses seem to be common for malaria antigens.

\section{Conclusion}

Viewed together, the antibody responses measured to MSP1 block 2 and MSP2 suggest that singly infected adults have a very different immune response in comparison with those living in malaria-endemic areas. It appears that antibodies to MSP1 block 2 become much more common with repeated infection while those to MSP2 become dominated by allelic family specificities particularly to the central amino acid repeat region with extinction of responses to the conserved region. The development of cross allelic-family reactive MSP2 antibodies after a single native infection with $P$. falciparum has been documented. These data strongly support the use of MSP2 for malaria vaccination. These data are also supportive of $M S P 1_{19}$ vaccine development given it was highly immunogenic after single infection with functional antibodies measured. As functional MSP $1_{19}$ antibodies have been shown to be correlated with protection [20] it now appears to be imperative to develop assays to test for functional antibodies in future vaccine trials of other antigens, such as MSP2.

\section{Authors' contributions}

DE conceived of the study, was responsible for its design and coordination, performed the statistical analysis and drafted the manuscript. LW carried out the antibody assays and reviewed the manuscript. HJ carried out the MSP1 block 2 antibody assays. EM and CB carried out the $\mathrm{MSP}_{19}$ invasion inhibition assays. OMP participated in the design of the study and contributed to the drafting of the manuscript. RC conceived of the study, and participated in its design and coordination and helped to draft the manuscript. All authors read and approved the final manuscript.

\section{Acknowledgements}

The authors neither have commercial nor other associations that might pose a conflict of interest in reporting this study. DE received funding for this study from the CSL Fellowship in Medical Research, Royal Australasian College of Physicians. LW, CB, EM and RC received funding from the Australian National Health and Medical Research Council. We would like to thank Matthew O'Sullivan for assistance with patient recruitment and Danny Wilson for technical assistance.

\section{References}

I. Miller LH, Roberts T, Shahabuddin M, McCutchan TF: Analysis of sequence diversity in the Plasmodium falciparum merozoite surface protein-I (MSP-I). Mol Biochem Parasitol 1993, 59:I-I4.

2. O'Donnell RA, de Koning-Ward TF, Burt RA, Bockarie M, Reeder JC, Cowman AF, Crabb BS: Antibodies against merozoite surface protein (MSP)-I(19) are a major component of the invasioninhibitory response in individuals immune to malaria. J Exp Med 200I, 193:|403-I4I2.

3. Moore SA, Surgey EG, Cadwgan AM: Malaria vaccines: where are we and where are we going? Lancet Infect Dis 2002, 2:737-743.

4. Conway DJ, Cavanagh DR, Tanabe K, Roper C, Mikes ZS, Sakihama N, Bojang KA, Oduola AM, Kremsner PG, Arnot DE, Greenwood $B M$, McBride JS: A principal target of human immunity to malaria identified by molecular population genetic and immunological analyses. Nat Med 2000, 6:689-692.

5. Genton B, Betuela I, Felger I, Al-Yaman F, Anders RF, Saul A, Rare L, Baisor M, Lorry K, Brown GV, Pye D, Irving DO, Smith TA, Beck HP, Alpers MP: A recombinant blood-stage malaria vaccine reduces Plasmodium falciparum density and exerts selective pressure on parasite populations in a phase $1-2 b$ trial in Papua New Guinea. J Infect Dis 2002, 185:820-827.

6. Wang L, Black CG, Marshall VM, Coppel RL: Structural and antigenic properties of merozoite surface protein 4 of Plasmodium falciparum. Infect Immun 1999, 67:21 193-2200.

7. Marshall VM, Tieqiao W, Coppel RL: Close linkage of three merozoite surface protein genes on chromosome 2 of Plasmodium falciparum. Mol Biochem Parasitol 1998, 94:13-25.

8. Goschnick MW, Black CG, Kedzierski L, Holder AA, Coppel RL: Merozoite surface protein 4/5 provides protection against lethal challenge with a heterologous malaria parasite strain. Infect Immun 2004, 72:5840-5849.

9. Wang L, Crouch L, Richie TL, Nhan DH, Coppel RL: Naturally acquired antibody responses to the components of the Plasmodium falciparum merozoite surface protein I complex. Parasite Immunol 2003, 25:403-4I2.

10. Topolska AE, Richie TL, Nhan DH, Coppel RL: Associations between responses to the rhoptry-associated membrane antigen of Plasmodium falciparum and immunity to malaria infection. Infect Immun 2004, 72:3325-3330.

II. Nixon CP, Friedman JF, Knopf PM, Duffy PE, Kurtis JD: Protective human immunity as a vaccine discovery tool for falciparum malaria. Transfusion 2005, 45:8IS-87S.

12. Eisen DP, Saul A, Fryauff DJ, Reeder JC, Coppel RL: Alterations in Plasmodium falciparum genotypes during sequential infections suggest the presence of strain specific immunity. $\mathrm{Am} J$ Trop Med Hyg 2002, 67:8-16.

13. Eisen D, Billman-Jacobe H, Marshall VF, Fryauff D, Coppel RL: Temporal variation of the merozoite surface protein-2 gene of Plasmodium falciparum. Infect Immun 1998, 66:239-246.

14. Burghaus PA, Holder AA: Expression of the 19-kilodalton carboxy-terminal fragment of the Plasmodium falciparum merozoite surface protein- $I$ in Escherichia coli as a correctly folded protein. Mol Biochem Parasitol 1994, 64:165-169.

15. Weisman S, Wang L, Billman-Jacobe H, Nhan DH, Richie TL, Coppel $\mathrm{RL}$ : Antibody responses to infections with strains of Plasmodium falciparum expressing diverse forms of merozoite surface protein 2. Infection and Immunity 200I, 69:959-967.

16. Egan AF, Chappel JA, Burghaus PA, Morris JS, McBride JS, Holder AA, Kaslow DC, Riley EM: Serum antibodies from malaria-exposed people recognize conserved epitopes formed by the two epi- 
dermal growth factor motifs of MSPI(19), the carboxy-terminal fragment of the major merozoite surface protein of Plasmodium falciparum. Infect Immun 1995, 63:456-466.

17. Wang L, Richie TL, Stowers A, Nhan DH, Coppel RL: Naturally acquired antibody responses to Plasmodium falciparum merozoite surface protein $\mathbf{4}$ in a population living in an area of endemicity in Vietnam. Infect Immun 200I, 69:4390-4397.

18. Jouin H, Rogier C, Trape JF, Mercereau-Puijalon O: Fixed, epitopespecific, cytophilic antibody response to the polymorphic block 2 domain of the Plasmodium falciparum merozoite surface antigen MSP-I in humans living in a malaria-endemic area. Eur J Immunol 200 I, 3 I:539-550.

19. Taylor RR, Smith DB, Robinson VJ, McBride JS, Riley EM: Human antibody response to Plasmodium falciparum merozoite surface protein $\mathbf{2}$ is serogroup specific and predominantly of the immunoglobulin $\mathbf{G 3}$ subclass. Infect Immun 1995, 63:4382-4388.

20. John CC, O'Donnell RA, Sumba PO, Moormann AM, de KoningWard TF, King CL, Kazura JW, Crabb BS: Evidence that invasioninhibitory antibodies specific for the 19-kDa fragment of merozoite surface protein-I (MSP-I 19) can play a protective role against blood-stage Plasmodium falciparum infection in individuals in a malaria endemic area of Africa. J Immunol 2004, 173:666-672.

21. Corran PH, O'Donnell RA, Todd J, Uthaipibull C, Holder AA, Crabb $B S$, Riley EM: The fine specificity, but not the invasion inhibitory activity, of 19-kilodalton merozoite surface protein Ispecific antibodies is associated with resistance to malarial parasitemia in a cross-sectional survey in The Gambia. Infect Immun 2004, 72:6185-6I89.

22. Perraut R, Marrama L, Diouf B, Sokhna C, Tall A, Nabeth P, Trape JF, Longacre S, Mercereau-Puijalon O: Antibodies to the conserved C-terminal domain of the Plasmodium falciparum merozoite surface protein $I$ and to the merozoite extract and their relationship with in vitro inhibitory antibodies and protection against clinical malaria in a Senegalese village. J Infect Dis 2005, 191:264-27I.

23. Cavanagh DR, Dodoo D, Hviid L, Kurtzhals JA, Theander TG, Akanmori BD, Polley S, Conway DJ, Koram K, McBride JS: Antibodies to the N-terminal block 2 of Plasmodium falciparum merozoite surface protein I are associated with protection against clinical malaria. Infect Immun 2004, 72:6492-6502.

24. Cavanagh DR, Elhassan IM, Roper C, Robinson VJ, Giha $\mathrm{H}$, Holder AA, Hviid L, Theander TG, Arnot DE, McBride JS: A longitudina study of type-specific antibody responses to Plasmodium falciparum merozoite surface protein- $I$ in an area of unstable malaria in Sudan. J Immunol 1998, 161:347-359.

25. Fluck C, Smith T, Beck HP, Irion A, Betuela I, Alpers MP, Anders R, Saul A, Genton B, Felger I: Strain-specific humoral response to a polymorphic malaria vaccine. Infect Immun 2004 72:6300-6305.

26. Felger I, Steiger S, Hatz C, Smith T, Beck HP: Antigenic cross-reactivity between different alleles of the Plasmodium falciparum merozoite surface protein 2. Parasite Immunol 2003, 25:53I-543.

27. Franks S, Baton L, Tetteh K, Tongren E, Dewin D, Akanmori BD, Koram KA, Ranford-Cartwright L, Riley EM: Genetic diversity and antigenic polymorphism in Plasmodium falciparum: extensive serological cross-reactivity between allelic variants of merozoite surface protein 2. Infect Immun 2003, 71:3485-3495.

28. Metzger WG, Okenu DM, Cavanagh DR, Robinson JV, Bojang KA Weiss HA, McBride JS, Greenwood BM, Conway DJ: Serum IgG3 to the Plasmodium falciparum merozoite surface protein 2 is strongly associated with a reduced prospective risk of malaria. Parasite Immunol 2003, 25:307-3I2.

29. Taylor RR, Allen SJ, Greenwood BM, Riley EM: IgG3 antibodies to Plasmodium falciparum merozoite surface protein 2 (MSP2): increasing prevalence with age and association with clinical immunity to malaria. Am J Trop Med Hyg 1998, 58:406-4I3.

30. Staalsoe T, Megnekou R, Fievet N, Ricke CH, Zornig HD, Leke R, Taylor DW, Deloron P, Hviid L: Acquisition and decay of antibodies to pregnancy-associated variant antigens on the surface of Plasmodium falciparum-infected erythrocytes that protect against placental parasitemia. I Infect Dis 200I, 184:618-626.
Publish with Biomed Central and every scientist can read your work free of charge

"BioMed Central will be the most significant development for disseminating the results of biomedical research in our lifetime. "

Sir Paul Nurse, Cancer Research UK

Your research papers will be:

- available free of charge to the entire biomedical community

- peer reviewed and published immediately upon acceptance

- cited in PubMed and archived on PubMed Central

- yours - you keep the copyright 